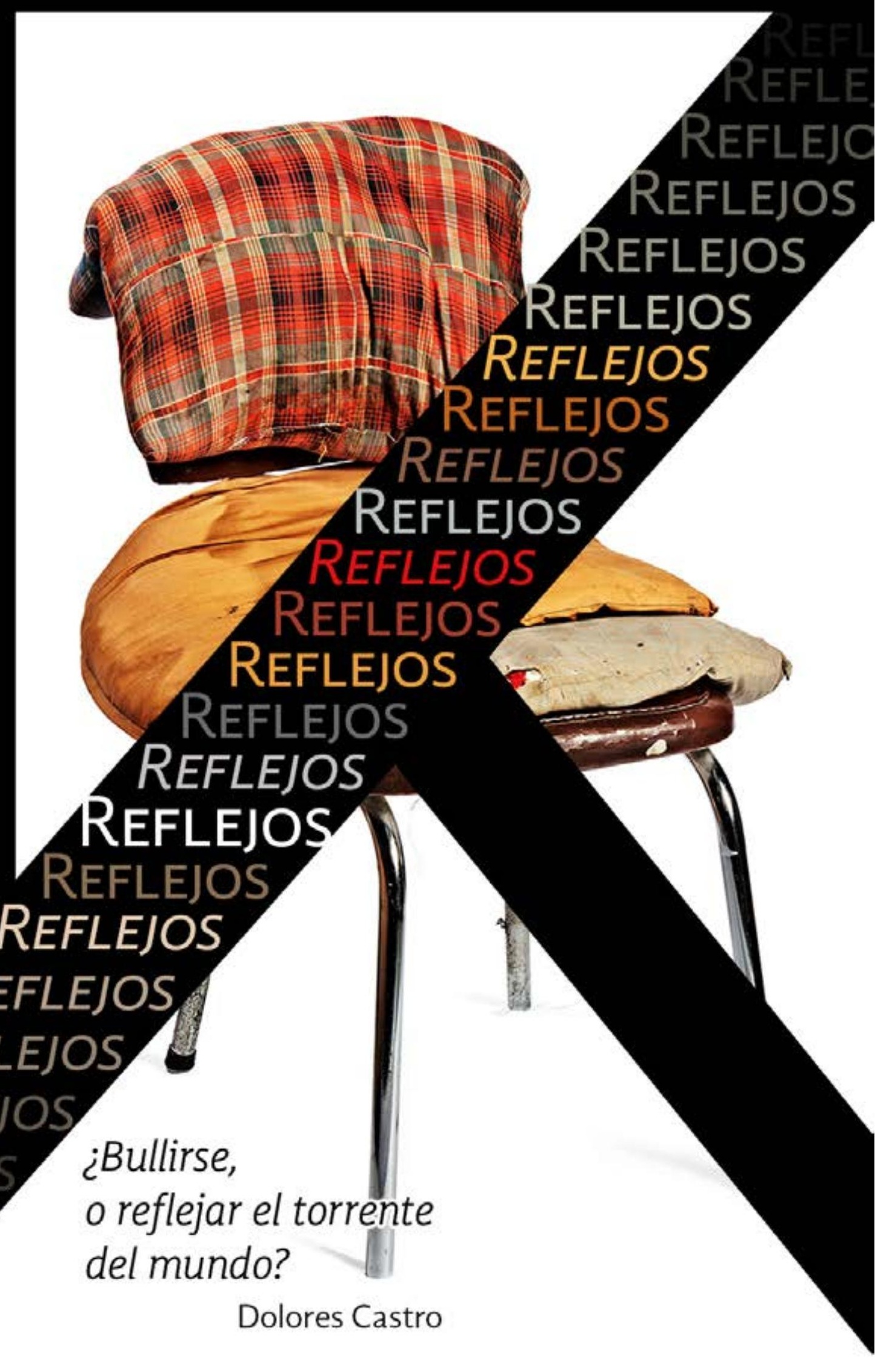




\section{El otro corazón de las tinieblas en Venezuela}

\section{CARLOS SANDOVAL}

Crítico literario, estudioso de la narrativa venezolana, editor, universitario de arraigo; sigue atento, acucioso, el rumbo de la literatura de su país. Aceptó responder un cuestionario y de aquí se desprende un panorama nada promisorio, a la vez que un reconocimiento a las letras de aquel gran pedazo de Sudamérica.

\section{¿Cuándo comenzó la diáspora de artistas venezolanos y qué autores represen- tativos salieron del país?}

Una vez que Chávez llega al poder -asume el cargo en febrero de 1999- su manera de gobernar cambia las formas políticas que hasta ese momento conocíamos. Se desvirtúan las maneras civiles que veníamos practicando en Venezuela desde 1958, cuando se produce la irrupción de la democracia representativa luego de la dictadura de Marcos Pérez Jiménez.

Hacia 2001 mucha gente comienza a pensar que el rumbo del país no es el más adecuado. En 2002, cuando se produce el golpe de Estado que mantuvo a Chávez fuera del poder por cuarenta y ocho horas, comenzó esto que ahora casi todos llaman "diáspora”. En principio, se marcharon muchos venezolanos de los estratos sociales superior y de clase media profesionalizada. Luego, al morir Chávez en 2013 y asumir Maduro, se recrudece la emigración porque se radicalizan las formas de manejo público, económico y político del país. Entonces es cuando hay una mayor salida de otras clases sociales: media baja y baja; miles de compatriotas de este último estrato se han salido de Venezuela incluso caminando hasta Colombia, Perú y Ecuador.

Por otra parte, entre el 2001 y 2010 hubo una suerte de boom editorial porque algunas casas editoras transnacionales, como Ediciones B, Editorial Planeta, el Grupo Norma y Random House se percataron de que había un filón interesante que desde la ensayística trataba de explicar las razones, las causas, los mecanismos que condujeron a Venezuela a lo que Chávez llamaría después "la revolución bolivariana”. Así aparecieron muchos trabajos periodísticos que, por ejemplo, editó e imprimió en Caracas Random House -y que tuvieron cierto éxito simbólico y crematístico- en su colección Debate.

Eso dio algo de impulso al mercado del libro, al punto de que las mismas casas editoriales comenzaron a publicar otros materiales literarios, sobre todo narrativa e investigaciones históricas y de corte sociológico. En ese boom participaron muchos autores a quienes correspondía ocupar -por razones de la dinámica cultural, en la perspectiva de Bourdieu- los espacios que iban dejando los escritores anteriores (de otros períodos) y que comenzaron a colonizar el imaginario venezolano apoyados por algunas de las editoriales mencionadas e incluso por algunas del Estado. 
Casi todos esos autores, que publican sus primeros libros apenas despunta este siglo XXI, se fueron del país en el transcurso de los últimos cinco, diez años: Carlos Ávila, Rodrigo Blanco Calderón, Roberto Echeto, Dayana Fraile, Enza García Arreaza, Gabriel Payares, Fedosy Santaella, para citar algunos ejemplos. De una generación muy anterior, digamos, es Alberto Barrera Tyszka, asentado en México, quien tiene una obra representativa, reconocida con premios importantes en el lapso que comento. También podríamos destacar a Ibsen Martínez, otro autor importante de la Venezuela de finales de los noventa, hoy en Bogotá y que ha publicado hasta ahora tres novelas.

Estos autores se marcharon del país por razones de carácter económico y de superación personal y espiritual, más que por razones políticas, pero siguen escribiendo con base en un imaginario anclado preferentemente en Venezuela.

¿Cómo se está moviendo la literatura producida allá, con qué canales? ¿Cómo se mueve lo electrónico en tiempos de falta de electricidad? ¿Qué editorial se ha ido, cuál se ha quedado y cuál ha nacido?

El panorama es precario. Las editoriales en Venezuela han disminuido su producción; de hecho hoy no queda ninguna casa transnacional operando en el país. Las filiales de las editoriales internacionales se marcharon porque el sistema financiero controlado no permitía la recuperación de sus inversiones. Las editoriales del Estado, debe decirse, continúan produciendo, pero a niveles mínimos.

La última feria del libro que organizó el Estado en la Plaza Bolívar de Caracas se hizo en un espacio reducido, en comparación con lo que solía ser esa feria en un parque abierto como Los Caobos o en las áreas del Teatro Teresa Carreño. Casi no hubo novedades editoriales porque los costos son altísimos. En este sentido, hasta el mismo Estado se ha visto un poco incapacitado de publicar a un ritmo sostenido.

Así pues, el mundo editorial venezolano se ha reducido a expresiones irrisorias. Como coordinador de ediciones de la pequeña y modesta Editorial Madera Fina puedo dar cuenta de que el último año solo publicamos un título gracias a que conseguimos financiamiento de algunos amigos. Hace poco reeditamos, también con ayuda de algún mecenas, la novela The $\mathrm{Ni}$ gth, de Rodrigo Blanco Calderón, a propósito del Premio Internacional de Novela Mario Vargas Llosa que la obra se adjudicó en 2019.

En este ennegrecido panorama ciertas empresas se mantienen publicando, pero los tirajes son reducidos y los títulos ralean. Del 2001 hasta 2019 aparecieron algunas pequeñas editoriales que momentáneamente dominaron el mercado literario: bid \& co. editor, Libros del Fuego (en este momento con buena proyección porque ha conseguido establecer sus operaciones fuera del país), Madera Fina, FB Libros, Fundavag. Hace poco el escritor Alberto Barrera Tyszka unió esfuerzos con la Librería Sopa de letras, de Caracas, y fundaron Curiara, que hasta ahora ha publicado dos títulos, entre ellos la novela del propio Barrera Tyszka Mujeres que matan, en edición solo para Venezuela. Hay que decir que el trabajo de algunas universidades ha sido también loable, en especial el que realiza Equinoccio, editorial de 
la Universidad Simón Bolívar, y ABediciones, de la Universidad Católica Andrés Bello.

Las casas editoriales del Estado editan una que otra obra. Algunas editoriales privadas han establecido un sistema que consiste en que los autores aportan una suma importante para publicar sus trabajos (una suerte de auto-publicación) y de ese modo pueden llegar a las librerías. Las editoriales universitarias, como las ya mencionadas Equinoccio (pública) y ABediciones (privada), y la de la Universidad de Los Andes, de la Universidad Central de Venezuela, de la Universidad del Zulia (estas tres públicas), de la Universidad Metropolitana (privada) publican poco e intentan migrar su producción al formato electrónico, que en entre nosotros no tiene mucha salida porque no tenemos fácil acceso a los dispositivos requeridos para ese soporte de lectura debido a las dificultades relacionadas con el control cambiario.

Claro que ha habido, no obstante, iniciativas editoriales para fomentar el mercado de libros electrónicos; pero acá muy pocos o nadie compra libros en esa presentación. Lo que ha ocurrido, más bien, es que algunas editoriales utilizan esas plataformas electrónicas como repositorio de sus materiales porque hasta ahora el lector venezolano no se ha acostumbrado a la lectura electrónica.

Por supuesto, muchos leemos libros electrónicos cuando tenemos el dispositivo e incluso libros en PDF que nos fusilamos de plataformas piratas. Es lo que nos permite mantenernos al día -lo digo con toda la responsabilidad del caso y consciente de que se trata de una práctica fraudulenta, tanto más viniendo de alguien que trabaja en el sector editorial-, pero es que hoy no hay en Venezuela ninguna posibilidad de explotar el mundo electrónico del libro (sin mencionar la cotidianidad de las fallas eléctricas que dificultan todo, además de la poca potencia de nuestros servicios de internet). Para no hablar de la importación de libros que prácticamente despareció.

¿Cómo opera, si opera, la censura o la autocensura en la literatura venezolana?

En los primeros años del mandato de Hugo Chávez -hablo desde mi experiencia como crítico literario-, cuando Monte Ávila Editores era regentada por Carlos Noguera, uno de nuestros escritores más importantes, esa casa editorial del Estado mostró una apertura ideológica de la cual fui beneficiario, pese a mi adversa posición política respecto del autodenominado proyecto de "revolución bolivariana". Así, en Monte Ávila y en algunas otras editoriales del Estado no ha habido realmente, o al menos yo no lo he percibido, una política estatal de censura.

Lo que sí ha habido es autocensura de parte de algunos autores que no están de acuerdo con las políticas económicas, sociales, culturales instrumentadas por el régimen de Chávez y su deriva en Maduro y que, debido a ello, se niegan a ser editados por casas estadales (Casa de las Letras Andrés Bello, Fundarte, el Centro de Estudios Latinoamericanos Rómulo Gallegos -Celarg-, Biblioteca Ayacucho, El perro y la rana, Monte Ávila). Una posición, por lo demás, legítima. De manera que no percibo una práctica de censura sistemática o coherente por parte del Gobierno; por el contrario, lo que he observado -repito- en el transcurso de estos años es una frontal autocensura por parte de algunos autores. 
Ahora bien, ha habido casos de intelectuales que por poner algún tuit contra alguna situación política o por criticar acciones procedimentales del Gobierno o por simplemente mencionar a algún funcionario del Estado de manera irónica o acerba han sido puestos en prisión y juzgados; o se han visto en la urgencia de abandonar el país.

Imagino, además, que algunos autores practican autocensura al momento de escribir sus textos. Sin embargo, en estos veinte años abunda la narrativa venezolana que con alguna frecuencia recrea temas relativos al contexto sociocultural y, por supuesto, político. Autores como Rodrigo Blanco Calderón, (cuando vivía en el país) escribía -en clave ficcional, se entiende- en contra de las formas que caracterizan los manejos administrativos e idiosincrásicos, digamos, de la revolución bolivariana. Pero no solo él; también Enza García, Federico Vegas, Francisco Suniaga... En fin, no observo que los narradores se hayan contenido al momento de hacer algún tipo de señalamiento respecto de lo que estamos viviendo.

Complemento, sin embargo, con el caso de Israel Centeno, quien denunció públicamente ser objeto de persecución por parte del Go-

bierno. Centeno es autor de la novela El complot (2002) en la que se narra el intento de asesinato del presidente de una república latinoamericana; presidente cuyas maneras de gobernar se parecían mucho a las de Hugo Chávez. A Centeno se le concedió asilo político en Estados Unidos donde actualmente vive.

\section{¿Cómo es el comercio de los libros en medio de la crisis?}

Desde hace cerca de cinco años el mercado librero, como el mundo editorial venezolano, se ha visto drásticamente reducido. Dos de las cadenas de librerías más importantes, Nacho y Tecni-ciencia, han cerrado muchas de sus tiendas en varias ciudades del país. Hace unas semanas, pongo otro ejemplo, recibí un tuit de un colega en el que me avisaba que una reconocida librería estaba rematando su fondo a precios bajísimos porque decidió cerrar.

Hoy no parece ser negocio tener una librería.

El sector editorial y el mercado del libro languidecen.

Tanto que en las pocas ferias que se siguen haciendo - el año pasado una del Estado y otra privada (la Feria del Libro del Oeste en la Universidad Católica Andrés Bello)- lo que destaca es el libro usado, de segunda mano.

Una posibilidad es vender los libros por Amazon. Algunos lo hacen, pero no puedes comprar ejemplares desde Venezuela. Es solo para su venta en el exterior. De modo que el mercado está comercialmente deprimido. El último mes Madera Fina apenas vendió catorce unidades. 
Muchos autores venezolanos escriben hoy desde fuera del país: Alemania, Argentina, Australia, Colombia, Chile, Ecuador, España, Estados Unidos, Inglaterra, Israel, México, Perú. En el caso de la narrativa, escriben novelas y cuentos donde el país que dejaron aparece retratado o apenas mencionado como telón de fondo de las acciones, pero sin duda mezclado con asuntos propios de personajes que habitan otros espacios nacionales y viven situaciones distintas a las venezolanas.

Hay que decir, también, que el lector que salió del país trata de mirar -desde su afuera- qué se publica en Venezuela que le permita formarse una idea de la situación. Es decir, estamos de moda por razones, lamentablemente, negativas. Algunos autores en España -el caso de Karina Sáinz Borgo con La hija de la española- se han transformado en fenómenos de ventas porque recrean cierta realidad venezolana de los últimos años: cómo opera, según su visión estético-narrativa, una Estado nacional bajo el dominio de una parcialidad política de izquierda, que dirige los asuntos públicos de una manera, en muchos casos, incivil.

Fuera del país el lector, que a ratos es también escritor, no sabría decir si ha sufrido alguna transformación comparado, digamos, con la manera como leía en otros lapsos de nuestra historia. Lo que sí es palpable es que, extramuros, el lector venezolano de narrativa anda, grosso modo, tras la búsqueda de sentido respecto de esto que vivimos socialmente: busca explicaciones, en fin, sobre lo que nos ha ocurrido (y ocurre).

Por su parte, el lector de narrativa que continúa en el país podríamos dividirlo, políticamente (o de manera parcializada) en aquellos que leen textos donde la representación negativa de los procederes del Gobierno es ostensible, y aquellos que leen materiales en los que la visión gobiernera, llamémosla así, resulta edificante. Me apresuro a señalar que estas son tentativas de hipótesis sustentadas en percepciones críticas también parcializadas -las mías-, pues en Venezuela no hay estadísticas de lectura fiables o algún sondeo sistemático, serio, sobre la materia.

¿Existen autores de la institucionalidad? ¿Cómo se manifiestan, cuál es su mérito?

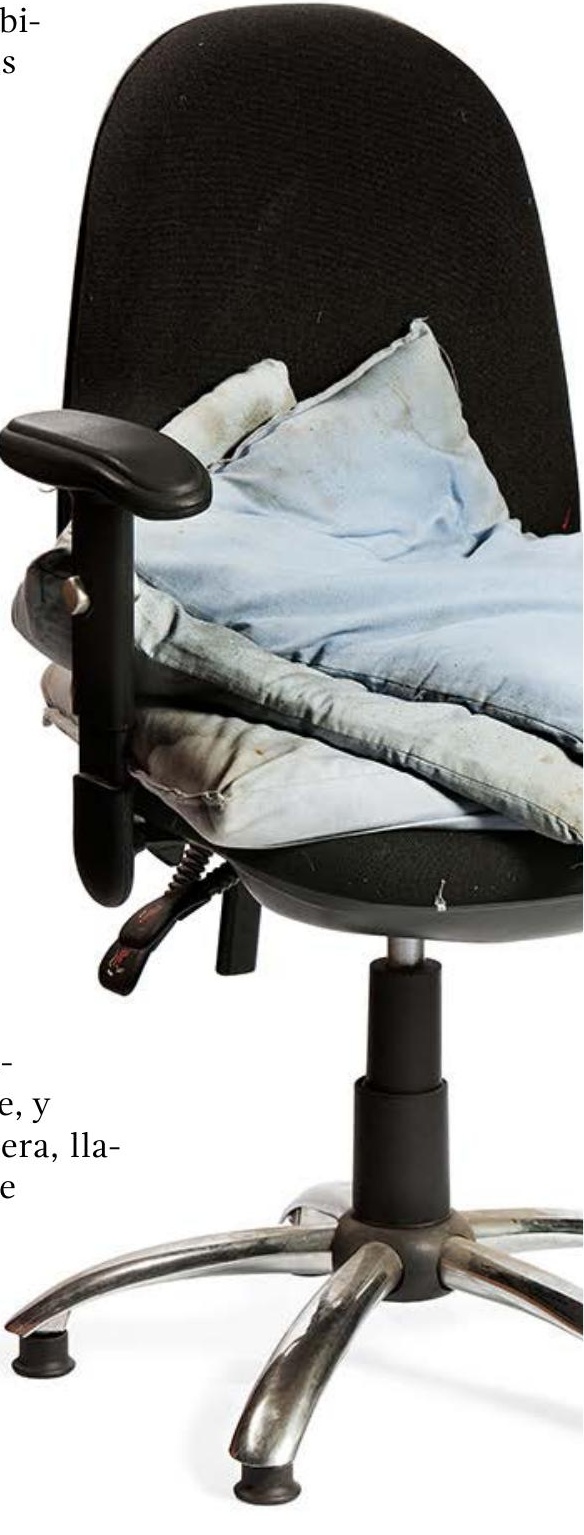

Tenemos escritores que han tenido importantes cargos en el Gobierno, voceros consecuentes de la Revolución Bolivariana. Los casos, por ejemplo, del narrador y ensayista Luis Britto García, y de los poetas Gustavo Pereira y Luis Alberto Crespo, los más visibles. O del narrador Carlos 
Noguera, quien hasta el momento de su fallecimiento fue presidente de Monte Ávila Editores. Los cuatro son autores con importantes obras concebidas y publicadas desde los tiempos de la democracia representativa.

Lo curioso es que algunos de estos escritores, como Luis Britto, publican ensayos y crónicas donde su posición partidista aparece claramente expuesta; sin embargo, en su trabajo narrativo han mantenido una posición neutra respecto de sus convicciones ideológico-políticas.

Esos autores publican en las editoriales del Estado. Probablemente tienen un público cautivo, pero como no disponemos de medios para calcular el universo de lectores solo podemos especular. Lo mismo ocurre en la acera contraria: hay una literatura venezolana consumida por un tipo de lector que hace parte de eso que llamamos la oposición. Tampoco sabemos cuántos son. La polarización y el enrarecimiento político del país ha llegado a tal extremo que podemos decir que hay lectores de ambas banderías; también críticos cuya postura les impide trabajar lo producido por el Estado al considerarse cabales oposicionistas. Y, claro, colegas del chavismo que no leen ni visitan lo que se publica del otro lado.

\section{¿Obras narrativas fundamentales del último lustro?}

Pues, la novela The Nigth, de Rodrigo Blanco Calderón, es una obra que críticamente ha dado mucho de qué hablar, desde el punto de vista estético y por los temas que allí se tratan. El autor ha ido consolidando su trabajo narrativo, primero como cuentista y luego como novelista (su segunda novela Simpatía, saldrá al mercado español en mayo próximo bajo el sello Alfaguara).

The Nigth cristaliza una serie de preocupaciones estéticas y temáticas que tienen que ver con el país. Se trata de una recreación (y acaso reinterpretación) de los años sesenta (siglo xx), los de la llamada "década violenta" cuando las guerrillas inspiradas (y apoyadas) por la revolución cubana quisieron dar al traste con el recién iniciado proyecto democrático; además, constituye un retrato de nuestra actualidad, una mirada sobre los modos de aplicación de la justicia en el país y, también, sobre cómo opera la política.

La novela pone asimismo en perspectiva la dinámica de la institución literaria. Es una pieza coral que cuenta la historia de un psiquiatra y de dos de sus amigos vinculados con la literatura. Paralelamente relata la vida del poeta Darío Lancini, un olvidado escritor venezolano reivindicado en el texto. Este argumento sirve para desgajar otros temas: casos emblemáticos de la justicia penal venezolana que impactaron la opinión pública y cierta recreación de lo que significó para muchos -en especial, para ciertos intelectuales- la década del sesenta respecto de los anhelos y la nostalgia por lo no concretado entonces políticamente y que, según se recoge en algunos trabajos críticos, se reflejaría como ideal -bastante difuminado- de lo que luego sería la revolución bolivariana. Advierto: The Nigth no justifica ese ideal. Por el contrario, la novela se posiciona claramente contra lo que hemos vivido estos últimos años.

La otra composición importante, de reciente data, es La hija de la española, sobre todo porque esta novela puso de nuevo en la mira al país -en 
otros contextos- gracias al tema que recrea. La obra refleja una situación social en un tono que se aproxima, con mucho, a una rauda y vertiginosa crónica en relación con lo vivido en Venezuela el último lustro. La novela podría calificarse como una rápida pintura de la revolución bolivariana entre 2013 y 2018. Su repercusión mediática ha sido impresionante. Independientemente de su materialidad artística, debe reconocerse que la novela ha servido para mostrar a un público amplio, internacional, diversas situaciones - con todo y que se trata de una ficción-que los venezolanos venimos padeciendo desde hace, al menos, dos décadas.

Habría que citar, asimismo, las novelas de Alberto Barrera Tyszka Patria o muerte y Mujeres que matan, también apegadas al referente histórico actual.

Puertas adentro hay novelas como las de Victoria de Stefano -cuya obra, en general, se reconoce como estéticamente bien resuelta, de densa tesitura y de gran resonancia intelectual-, pero que no ha calado en un público repentista ni, lamentablemente, ha tenido la proyección internacional que merece. En este mismo sentido tenemos el caso de Óscar Marcano, un esteta de la prosa cuya novela Puntos de sutura -un poco más remota que el último lustro solicitado- no ha tenido la repercusión que en otro contexto cultural sin duda hubiera alcanzado con rapidez. 